\title{
Mango Peel Ingredient as Salt and Phosphate Replacement in Chicken Breast Marinade
}

\author{
Sunisa Roidoung ${ }^{a^{*}}$, NAPATSAWAn Ponta $^{\mathrm{a}}$, And Ruttapong Intisan ${ }^{\mathrm{a}}$ \\ ${ }^{\text {a }}$ Faculty of Technology, Department of Food Technology and Nutrition, Maha Sarakham University, 44150 \\ Maha Sarakham, Thailand \\ ${ }^{*}$ Corresponding author \\ sunisa.r@msu.ac.th \\ TEL: +66-9-9084-6508 \\ FAX: $+66-4-3754-086$
}

Received: 14 August 2018; Published online: 18 April 2020

\begin{abstract}
Whole mango peel powder and fibre extracted from mango peel were investigated as potential ingredients to replace salt and phosphate in chicken marinade. Whole mango peel powder possessed higher water absorption capacity than mango peel fibre, $4.57 \%$ and $1.47 \%$, respectively $(\mathrm{P}<0.05)$. Similar oil absorption capacity was observed in both mango peel ingredients $(\mathrm{P}>0.05)$. Purified pectin and sorbitol syrup were also used to compare the water holding capacity in marinated chicken breasts. Mango peel ingredients exhibited less cooking loss than pectin and sorbitol syrup, however, higher cooking loss than sodium tripolyphosphate (STPP) and $\mathrm{NaCl}(\mathrm{P}>0.05)$. Marinating with mango peel ingredients significantly increased $\mathrm{a}^{*}$ value of chicken breasts after cooking, while $\mathrm{L}^{*}$ and $\mathrm{b}^{*}$ values were similar in marinating with $\mathrm{NaCl}(\mathrm{P}>0.05)$. Hardness of frozen fully cooked chicken breast was measured after thawing. The lowest shear force of $7.13 \mathrm{~N}$ was observed in chicken breasts marinated with mango peel fibre $(\mathrm{P}<0.05)$, while the hardness of chicken breasts marinated with whole mango peel powder was not significant different from STPP and $\mathrm{NaCl}$ treatments. Results from this study revealed a potential approach of utilizing fruit waste as an ingredient to substitute for phosphate and salt in chicken marinade.
\end{abstract}

Keywords: Low sodium; Low phosphate; Mango peel; Marinade; Chicken breast

\section{Introduction}

Frozen, fully cooked chicken products are typically consumed worldwide, both in households and in restaurant chains. In order to boost up flavour, marination is becoming a crucial step in preparing chicken products. Marinades not only develop the flavour and texture of the chicken products, but reduce weight loss in further processes such as roasting, baking, frying, and thawing. In addition to taste, the marinade recipe that could be absorbed and well retained in the chicken meat is very desirable. Most marinade solutions regularly add salt and phosphates. Salt or sodium chloride $(\mathrm{NaCl})$ provides a negative charge $\left(\mathrm{Cl}^{-}\right.$ion $)$to interact with positive charge on the myosin protein in chicken meat. This interaction induces the dissolving of insoluble myosin, hence the meat swells and is able to hold water. Moreover, salt and phosphates extract myofibrilla proteins to form a cohesive network on the meat surface, which could trap water upon cooking (Acton \& Jensen, 1994; Tarté, 2009). Although salt and phosphates have been generally used as food additives, consumers have currently a raised awareness of the sodium and 
194 Roidoung et al.

phosphate content in their foods. Sodium levels in food have become a serious concern due to its potential to cause high blood pressure and cardiovascular diseases. Additionally, excessive phosphate consumption could lead to hyperphosphataemia with kidney disease. Several research efforts have been made to test potential approaches to replacing or reducing salt and phosphate levels in the marinade, whilst maintaining percent yield and organoleptic properties. Uchupaj, Malila, Petracci, Benjakul and Visessanguan (2017) reported that using a proprietary recipe of non-phosphate and low-sodium salt (NPLS) marinade significantly reduced cooking loss, and it was found to be more effective on breast meat than thighs and drumsticks. The NPLS marinade contained potassium bicarbonate, potassium chloride and sorbitol. Jarvis et al. (2012) proposed dried plum ingredients to replace sodium tripolyphosphate (STPP) in marinating chicken breast fillet, providing similar sensory results and yield to the STPP marinade. With more health awareness, plant-based ingredients are gaining more attention. Mango is one of the tropical fruits available for consumption throughout the year, particularly in Thailand. In Thailand, mango is usually consumed when it is still green and just starts ripening. Mango peel is always discarded as waste. Ajila, Naidu, Bhat and Rao (2007), and Kanatt and Chawla (2018) revealed antioxidant, and antibacterial properties in mango peel extract. The incorporation of mango peel powder was found to increase total dietary fibre, and firmness in a macaroni preparation (Ajila, Aalami, Leelavathi \& Rao, 2010). In addition, mango peel has been reported to be a potential source of good pectin (Geerkens et al., 2015; Kermani, Shpigelman, Huong, Van Loey \& Hendrickx, 2015; Nagel et al., 2015; Wang et al., 2016). These investigations have revealed the health benefit component in mango peel, and its application. However, publications regarding the application of mango peel as a substitute for salt and phosphate are still limited. Therefore, this research was aimed to determine a potential approach of utilizing the natural ingredient for reducing salt and phosphate in chicken breast marinade. Physicochemical properties of frozen fully cooked chicken breast marinated with mango peel in- gredients were evaluated compared to marination with salt, phosphate, pectin, and sorbitol.

\section{Materials and Methods}

\subsection{Whole mango peel powder and fibre extracted from mango peel}

Mango peels of Fah Lan mango (Mangifera indica L.) were collected from a fruit trolley in Maha Sarakham province, Thailand. Mango peel was from mature stage of mango with fully developed green skin, and white colour of firm flesh. The mango peel was washed with tap water, drained, and dried in hot air oven (Memmert, Schwabach, Germany) at $60{ }^{\circ} \mathrm{C}$ for 4 hours. The dried peel was finely ground and kept in polyethylene bags. Fibre from mango peel was extracted using 250 grams of whole mango peel powder in $1.5 \mathrm{~L}$ of acidified water $(\mathrm{pH} 2.5-3$, $\mathrm{pH}$ adjusted using citric acid), and stirred until the mango powder was well dispersed. The solution was heated at $65{ }^{\circ} \mathrm{C}$ for 1 hour in a water bath (Memmert W200, Schwabach, Germany) with continuously stirring. The hot mixture was filtered through cheese cloth (fine grade, $100 \%$ cotton). Pectin was coagulated from the filtrate using equal volume of $95 \%$ ethanol (Analytical grade, VWR chemicals, Leighton Buzzard, England). The solution was left for 1 hour to let pectin float to the surface. Extracted pectin was skimmed off and washed 2 - 3 times with ethanol to remove remaining impurities. Finally, the pectin was dried at $40{ }^{\circ} \mathrm{C}$ for 4 hours in a hot air oven. The dried pectin was ground and kept in polyethylene bags for further use and analysis.

\subsection{Frozen fully cooked chicken breast}

Packaged raw chicken breasts (Tesco brand) were purchased from Tesco Lotus supermarket in Maha Sarakham province. The meat was cut, and each individual piece weighed to $50 \pm 3$ g. The temperature of the raw chicken breast was controlled by keeping it in a refrigerator $\left(4^{\circ} \mathrm{C}\right)$ for 3 hours before marination. There 
Mango peel ingredients in a chicken marinade | 195

Table 1: Six treatments of marinade

\begin{tabular}{lrrrrrr}
\hline \multirow{2}{*}{ Ingredient lists } & \multicolumn{7}{c}{ Ingredient amount (\%) } \\
\cline { 2 - 7 } & Trt \#1 & Trt \#2 & Trt \#3 & Trt \#4 & Trt \#5 & Trt \#6 \\
\hline Water & 90 & 90 & 90 & 90 & 90 & 90 \\
Corn starch & 8 & 8 & 8 & 8 & 8 & 8 \\
NaCl & 2 & 0 & 0 & 0 & 0 & 0 \\
STPP & 0 & 2 & 0 & 0 & 0 & 0 \\
Mango peel powder & 0 & 0 & 2 & 0 & 0 & 0 \\
Mango peel fibre & 0 & 0 & 0 & 2 & 0 & 0 \\
Pectin powder & 0 & 0 & 0 & 0 & 2 & 0 \\
70\% Sorbitol syrup & 0 & 0 & 0 & 0 & 0 & 2 \\
\hline All treatments
\end{tabular}

All treatments were prepared in triplicate.

were 6 marinade treatments as shown in Table 1. All 6 treatments contained $90 \%$ distilled water with $8 \%$ food graded corn starch (Krauwangthip brand, Smutsakorn Thailand), the remaining $2 \%$ of each treatment was sodium chloride $(\mathrm{NaCl}$, Univar $^{\circledR}$, Ajax Finechem Laboratory Chemicals, Australia), or sodium tripolyphosphate (STPP, Chemipan Corp, Bangkok, Thailand), or mango peel powder, or mango peel fibre, or purified pectin powder (Chemipan Corp, Bangkok, Thailand), or sorbitol syrup (70\% sorbitol syrup, Krungthepchemi Co., Ltd, Thailand). The $200 \mathrm{~g}$ chicken breasts (4 pieces of each $50 \mathrm{~g}$ meat cut) were mixed with $15 \%$ marinade solution. The mixing was gently done by hand in a stainless steel bowl for 2 minutes, the bowl wrapped with plastic and was then put in a refrigerator for 45 minutes to let the meat absorb the marinade.

Marinated chicken breasts were baked in a conventional oven (MEX oven, Pen K Life Center, Bangkok, Thailand) at $220{ }^{\circ} \mathrm{C}$ for 20 minutes, and internal temperature of the meat reached 75 ${ }^{\circ} \mathrm{C}$. The cooked breasts were frozen using an air blast freezer (iRiNOX, Aerosia interpac Co., Ltd, Bangkok, Thailand) for 15 minutes. The frozen fully cooked products were packed in freezer bags and stored at $-18{ }^{\circ} \mathrm{C}$. All six marinating treatments were done in triplicate.

\subsection{Physicochemical analysis}

\section{Moisture content}

Moisture content of whole mango peel powder or extracted fibre from mango peel was analyzed based on the AOAC (2005) method. Briefly, the sample $(5 \mathrm{~g})$ was weighed in a pre-weighed moisture can, and dried at $105{ }^{\circ} \mathrm{C}$ overnight in a hot air oven. The moisture content was expressed as a percentage.

\section{Water and oil absorption capacities}

The water absorption capacity and oil absorption capacity of mango peel ingredients were determined by the methods described by Cheng and Bhat (2016), and Jan, Saxena and Singh (2016) with some modifications. Mango peel samples $(2 \mathrm{~g})$ were mixed in $20 \mathrm{~mL}$ distilled water or refined oil in a pre-weighed centrifuge tube. The mixture was stirred well and allowed to stand at room temperature $\left(28 \pm 2{ }^{\circ} \mathrm{C}\right)$ for an hour. Then the samples were centrifuged at $2000 \mathrm{x}$ g for 20 minutes. The supernatant was drained off and the sediment was weighed. The water absorption capacity or oil absorption capacity was expressed as weight of absorbed water or oil by one gram of mango peel sample.

\section{pH and Colour measurement}

The $\mathrm{pH}$ value of raw chicken breasts was recorded before marination using a pH meter (FiveEasy Plus, Mettler-Toledo, Kowloon, Hong Kong). 
Meanwhile, colour $\left(\mathrm{L}^{*}, \mathrm{a}^{*}, \mathrm{~b}^{*}\right)$ of chicken breast was measured before marination, after cooking, and after thawing, using a handheld colorimeter. $\mathrm{L}^{*}, \mathrm{a}^{*}, \mathrm{~b}^{*}$ values of mango peel ingredients were also measured using a handheld colorimeter (CR400 Chroma meter, Konica Minolta). All 4 chicken breast samples of each treatment were measured for colour $\mathrm{L}^{*} \mathrm{a}^{*} \mathrm{~b}^{*}$. The experiment was conducted in triplicate.

\subsection{Water holding capacity}

Water holding capacity of each treatment was determined by comparing $\%$ marinade pick up, $\%$ cooking loss, and \% thawing loss. The calculations were done using following equations;

$\%$ marinade pick up $=\frac{m_{\text {marinated }}-m_{\text {raw }}}{m_{\text {raw }}} \times 100$

$\%$ cooking loss $=\frac{m_{\text {marinated }}-m_{\text {cooked }}}{m_{\text {marinated }}} \times 100$

$\%$ thawing loss $=\frac{m_{\text {cooked }}-m_{\text {thawed }}}{m_{\text {cooked }}} \times 100$

$\%$ total loss $=\%$ cooking loss $+\%$ thawing loss - \%marinade pick up

Where:

$\mathrm{m}_{\text {raw }}=$ weight of raw chicken breast before marination

$\mathrm{m}_{\text {marinated }}=$ weight after 45 -minute marination

$\mathrm{m}_{\text {cooked }}=$ weight after cooking in an oven

$\mathrm{m}_{\text {thawed }}=$ weight after thawing overnight in a refrigerator

The overall mass (4 chicken breast samples) of each treatment was determined, with three replicates.

\section{Texture (hardness) analysis}

Hardness of thawed chicken breast was measured by Texture Profile Analysis (TPA) following the method of $\mathrm{Li}$ (2006). The thawed chicken breast was cut into $1.5-\mathrm{cm}$ cubes. Hardness of the sample was measured using a texture analyzer model TA-XT plus (Stable Micro Systems, United Kingdom), fitted with a 5-mm-diameter $\mathrm{P} / 6$ stainless steel cylindrical probe. The sample was placed on the plate so that its muscle fibres were aligned horizontally. The compression settings were: $2 \mathrm{~mm} \mathrm{~s}^{-1}$ pre-test speed, $1 \mathrm{~mm} \mathrm{~s}^{-1}$ test speed, $10 \mathrm{~mm} \mathrm{~s}^{-1}$ post-test speed, and distance was $70 \%$ strain. In each treatment, all 4 chicken breast samples were tested. The treatments were prepared in triplicate.

\subsection{Statistical analysis}

All data were reported as mean with standard deviation, and subjected to analysis of variance (ANOVA). Duncan's multiple range test (DMRT) was used to identify significant differences, with defined statistical level as $\alpha=0.05$. The statistical analysis was performed in SPSS Statistica 17.0 software.

\section{Results and discussion}

\subsection{Physicochemical properties of whole mango peel powder and mango peel fibre}

Water absorption capacity (WAC) of whole mango peel powder (4.57 g water/g dry peel powder) (Table 2 ) was found to be higher than WAC of extracted mango fibre $(1.47 \mathrm{~g}$ water $/ \mathrm{g}$ fibre) $(\mathrm{P}<0.05)$. However, the oil absorption capacities (OAC) of the two samples were not significantly different $(0.7-0.9 \mathrm{~g}$ oil/ g dry sample). Essmat, Marwa and Ferial (2017) reported WAC and OAC of citrus (orange and lemon) peel powder from four different cultivars, which varied from 1.53 - $3.83 \mathrm{~g}$ water/ g dry sample, and 0.89 - $1.37 \mathrm{~g}$ oil/g dry sample, respectively. In comparison to those results, whole mango peel powder exhibited outstanding WAC over peel powder from some citrus fruits. The ingredient with high WAC would be preferable to use in marinating, since it could help to increase water holding in the marinated meat. Moisture content of whole mango peel powder was significantly higher than moisture content of fibre extracted from mango peel. This may have been due to the double drying in fibre extraction process. This excess heat could have also given a darker colour in the extracted fibre sample $(\mathrm{P}<$ $0.05)$. 
Mango peel ingredients in a chicken marinade | 197

Table 2: Physicochemical properties of mango peel ingredients

\begin{tabular}{lcc}
\hline Analysis & Mango peel powder & Mango peel fibre \\
\hline WAC (g water/g dry powder) & $4.57 \pm 0.08^{a}$ & $1.47 \pm 0.01^{b}$ \\
OAC (g oil/ g dry powder) & $0.91 \pm 0.19^{a}$ & $0.70 \pm 0.12^{a}$ \\
Moisture content (\%) & $7.23 \pm 0.20^{a}$ & $5.13 \pm 0.21^{b}$ \\
$\mathrm{~L}^{*}$ value & $62.96 \pm 0.54^{a}$ & $52.82 \pm 0.49^{b}$ \\
$\mathrm{a}^{*}$ value & $4.19 \pm 0.24^{a}$ & $0.23 \pm 0.09^{b}$ \\
$\mathrm{~b}^{*}$ value & $26.13 \pm 1.46^{a}$ & $20.50 \pm 0.21^{b}$ \\
\hline Values are mean \pm standard deviation $(\mathrm{n}=3)$. Mean values in the same
\end{tabular}

Values are mean \pm standard deviation $(\mathrm{n}=3)$. Mean values in the same
row sharing different superscripts were significantly different $(\mathrm{P}<0.05)$.

Table 3: Water holding capacity of chicken breast marinated in different treatments

\begin{tabular}{lcccc}
\hline Treatment & $\begin{array}{c}\text { \% Marinade pick-up } \\
(1)\end{array}$ & $\begin{array}{c}\text { \% Cooking loss } \\
(2)\end{array}$ & $\begin{array}{c}\text { \% Thawing loss } \\
(3)\end{array}$ & $\begin{array}{c}\text { \% Total loss } \\
(3)+(2)-(1)\end{array}$ \\
\hline 1. STPP & $3.90 \pm 0.56^{a b}$ & $30.37 \pm 3.37^{a}$ & $1.01 \pm 0.45^{a}$ & $27.47 \pm 3.75^{b c}$ \\
2. NaCl & $4.74 \pm 1.32^{a}$ & $28.93 \pm 6.04^{a}$ & $2.10 \pm 1.24^{a}$ & $26.29 \pm 6.39 \mathrm{c}$ \\
3. Mango peel fibre & $3.14 \pm 0.23^{a b}$ & $33.61 \pm 2.46^{a}$ & $2.34 \pm 0.54^{a}$ & $32.81 \pm 2.55^{a b c}$ \\
4. Mango peel powder & $3.16 \pm 0.73^{a b}$ & $35.01 \pm 1.26^{a}$ & $2.08 \pm 0.78^{a}$ & $33.93 \pm 1.94^{a b}$ \\
5. Pectin & $3.76 \pm 0.29^{a b}$ & $36.65 \pm 2.26^{a}$ & $2.16 \pm 0.42^{a}$ & $35.05 \pm 2.51^{a}$ \\
6. Sorbitol Syrup & $2.14 \pm 1.15^{b}$ & $36.30 \pm 2.19^{a}$ & $1.95 \pm 0.31^{a}$ & $36.11 \pm 3.53^{a}$ \\
\hline
\end{tabular}

Values are mean \pm standard deviation $(n=3)$. Mean values in the same row sharing different superscripts $(\mathrm{a}, \mathrm{b}, \mathrm{c})$ were significantly different $(\mathrm{P}<0.05)$.

\subsection{Water holding capacity}

Water holding capacity of samples in different marinades were determined in terms of \%marinade pick up, \%cooking loss, \%thawing loss, and \%total loss (Table 3). After 45-minute marinating in a refrigerator, chicken breast marinated with $2 \% \mathrm{NaCl}$ showed the highest marinade pick up. Meanwhile, $2 \%$ sorbitol syrup gave the lowest pick up $(\mathrm{P}<0.05)$, in contrast to its wellrecognized absorbent functionality. The marinade pick up of all treatments reported in this study ranged from 2.14 to $4.74 \%$, which corresponded well to the result with chicken carcass of $4.09 \%$ (U-chupaj et al., 2017). However, vacuum marinating could increase marinade uptake to be $5.6-11.8 \%$ as reported by Jarvis et al. (2012). Water holding capacity in samples marinated with whole mango peel powder and extracted mango fibre were similar $(\mathrm{P}>0.05)$. Chicken breast in $2 \%$ pectin marinade presen- ted the highest cooking loss $(36.65 \%)$, while the highest thawing loss was found in the sample with $2 \%$ mango peel fibre $(2.34 \%)$. The highest cooking loss was found in $2 \%$ pectin marinade solution, which contrasted to the hypothesis in which pectin could help holding water through interaction between negative charge of carboxylic group and calcium ions to form an "egg box" structure, according to Rolin (1993). Zheng, Toledo and Wicker (1999) reported the limitation of using pectin in a chicken breast marinade due to the difficulty of pectin distribution. However, mango peel ingredients might provide pectin with better distribution, since lower cooking loss was found. According to \%total loss shown in Table 3, as expected, $\mathrm{NaCl}$ and STPP were the best two ingredients which gave the least loss. However, whole mango peel powder and mango peel fibre tended to provide better yields than pectin and sorbitol syrup. 


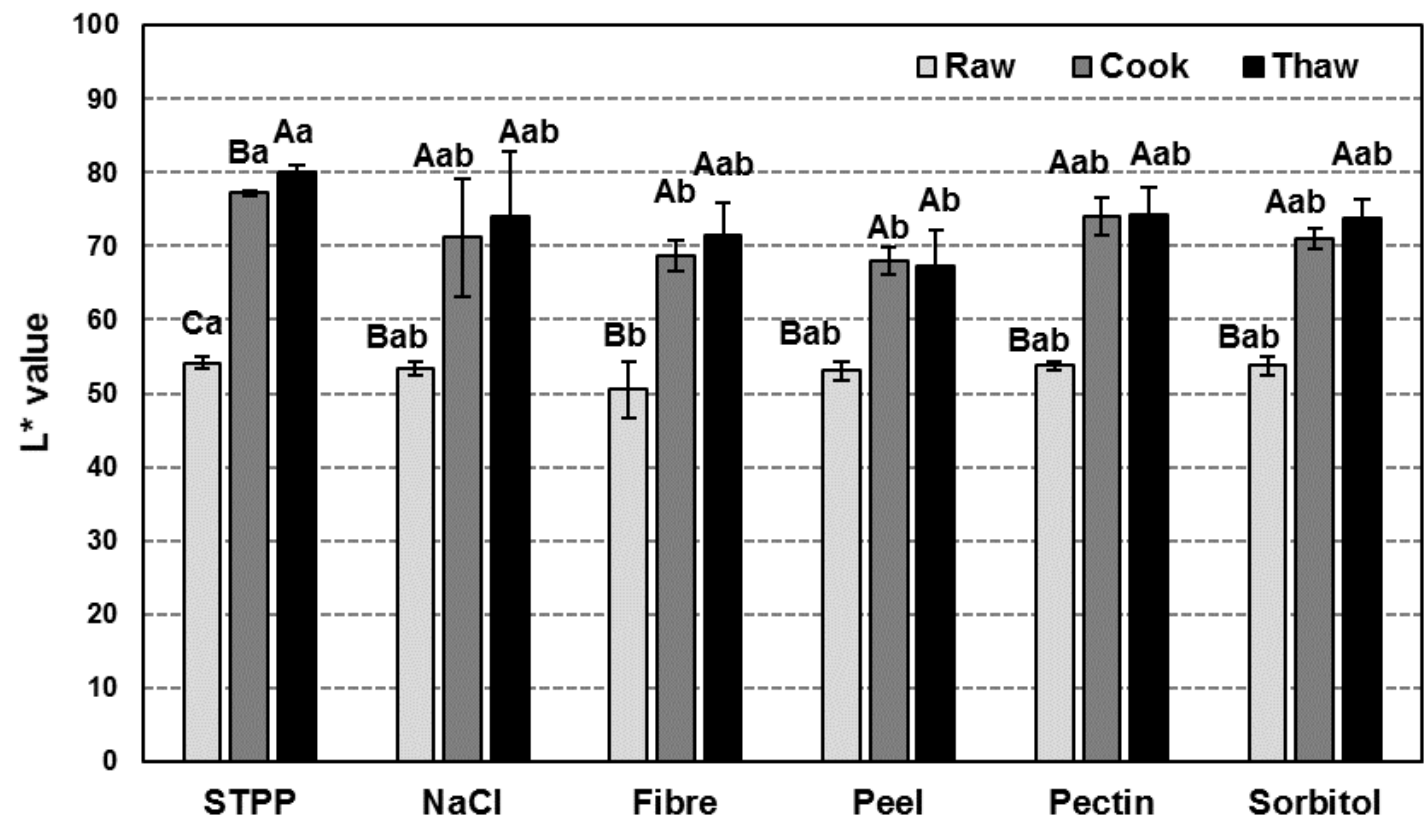

Figure 1: Effect of marinade treatments on lightness ( $\mathrm{L}^{*}$ value) of chicken breasts. Treatments sharing different letters $(\mathrm{A}, \mathrm{B}, \mathrm{C})$ and $(\mathrm{a}, \mathrm{b})$ were significantly different from each other within the same marinade and across different marinades, respectively $(\mathrm{P}<0.05)$.

\section{$3.3 \mathrm{pH}$ and colour}

The $\mathrm{pH}$ values of raw chicken breasts used in all treatments varied in a narrow range of 6.02 6.07 (data not shown), and the $\mathrm{L}^{*}, \mathrm{a}^{*}, \mathrm{~b}^{*}$ values of raw chicken breast used in the six treatments were not significantly different, which indicated the colour uniformity of raw material. Colour measurements are shown in Figures 1 - 3. Cooking significantly increased lightness ( $\mathrm{L}^{*}$ value), and thawing did not affect the lightness $(\mathrm{P}>$ 0.05) except STPP treatment where the lightness significantly increased after thawing (Figure 1). The lowest $\mathrm{L}^{*}$ value was found in the treatments with both mango ingredients $(\mathrm{P}<0.05)$, which corresponded to the darker colour of dried mango peel and extracted mango fibre. A similar darker colour in chicken breast was made with addition of plum extract puree (Lee \& Ahn, 2005). However, organoleptic testing would be necessary to identify whether this darker colour affected consumer acceptance. The $\mathrm{a}^{*}$ values (redness) of chicken breast decreased after cooking, except for the two treatments with mango peel ingredients $(\mathrm{P}<0.05)$ (Figure 2$)$. Moreover, in 5 out of 6 treatments, the redness slightly increased after thawing $(\mathrm{P}>0.05)$. The change in $\mathrm{b}^{*}$ values from raw meat to cooking and thawing in all six treatments followed the same trend (Figure 3). As shown, yellow colour developed on chicken breast after cooking $(\mathrm{P}<0.05)$, and the colour after thawing remained more intense than the raw. Among six treatments, marinating with STPP seemed to give a whiter colour, considering the highest lightness, and lowest red and yellow intensity. According to Figure 3, the levels of colour intensity in the yellow region were higher than the levels of redness (Figure 2), hence the yellow colour seemed to be dominant over the redness. 


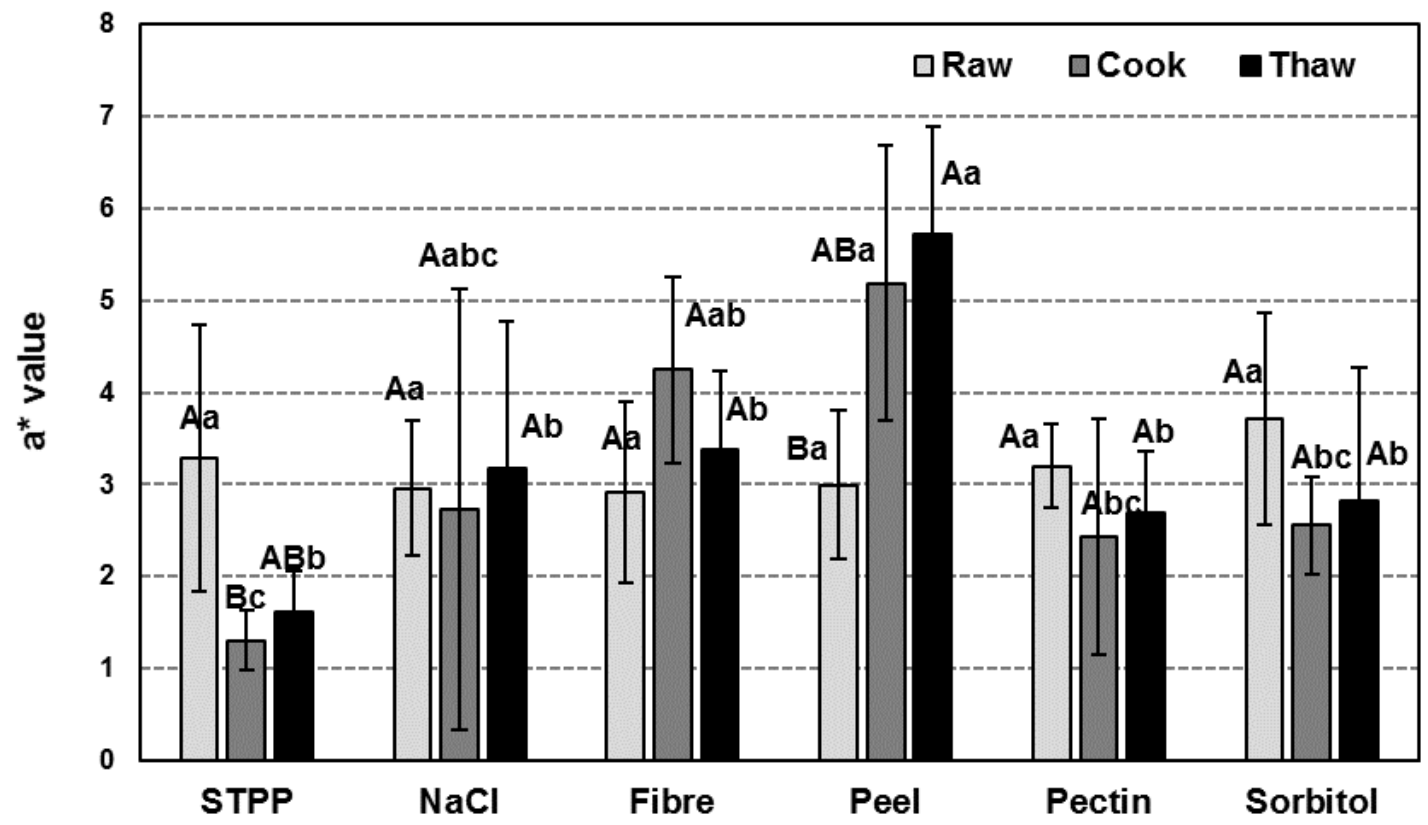

Figure 2: Effect of marinade treatments on red colour intensity ( $\mathrm{a}^{*}$ value) of chicken breasts. Treatments sharing different letters $(\mathrm{A}, \mathrm{B})$ and $(\mathrm{a}, \mathrm{b}, \mathrm{c})$ were significantly different from each other within the same marinade and across different marinades, respectively $(\mathrm{P}<0.05)$.

\subsection{Texture profile analysis}

With respect to ready-to-eat aspects, the hardness of the samples was measured after thawing (Table 4). Highest shear force was found in samples with sorbitol syrup $(10.45 \mathrm{~N})$, and STPP (10.38 N) marination, while the lowest force $(7.13 \mathrm{~N})$ was in mango peel fibre $(\mathrm{P}<$ $0.05)$. The hardness recorded in this study was similar to that reported by Jarvis et al. (2012), in which the shear force varied from $7.2-9.2$ N. Nunez de Gonzalez, Boleman, Miller, Keeton and Rhee (2008) concluded that increasing plum ingredient in ham marinade contributed to higher cooking loss and higher shear force. However, their conclusion did not seem to apply to the results in this study, especially when marinating with mango ingredients. To clarify, hardness of chicken breasts marinated with mango fibre was less than the samples in STPP marinade $(\mathrm{P}<0.05)$, even the STPP marinade exhibited higher water holding capacity. Although water-holding capacity in chicken breast samples marinated with whole mango peel powder could not fully match STPP and $\mathrm{NaCl}$, hardness of the samples was similar $(\mathrm{P}>0.05)$.

\section{Conclusions}

Mango peel ingredients were investigated for potential ingredients that could replace salt and phosphate in chicken marinade. Purified pectin and sorbitol syrup were used in this study to compare the water holding capacity in marinated chicken breasts. It was found that mango peel ingredients provided better water holding capacity than purified pectin and sorbitol syrup. After thawing, $\mathrm{L}^{*}, \mathrm{a}^{*}, \mathrm{~b}^{*}$ values of chicken breasts marinated with mango peel ingredients were similar to the colour values of chicken breasts marinated with STPP and salt $(\mathrm{P}>0.05)$. Although both mango peel powder and mango fibre were better than STPP and salt in chicken marination, when 


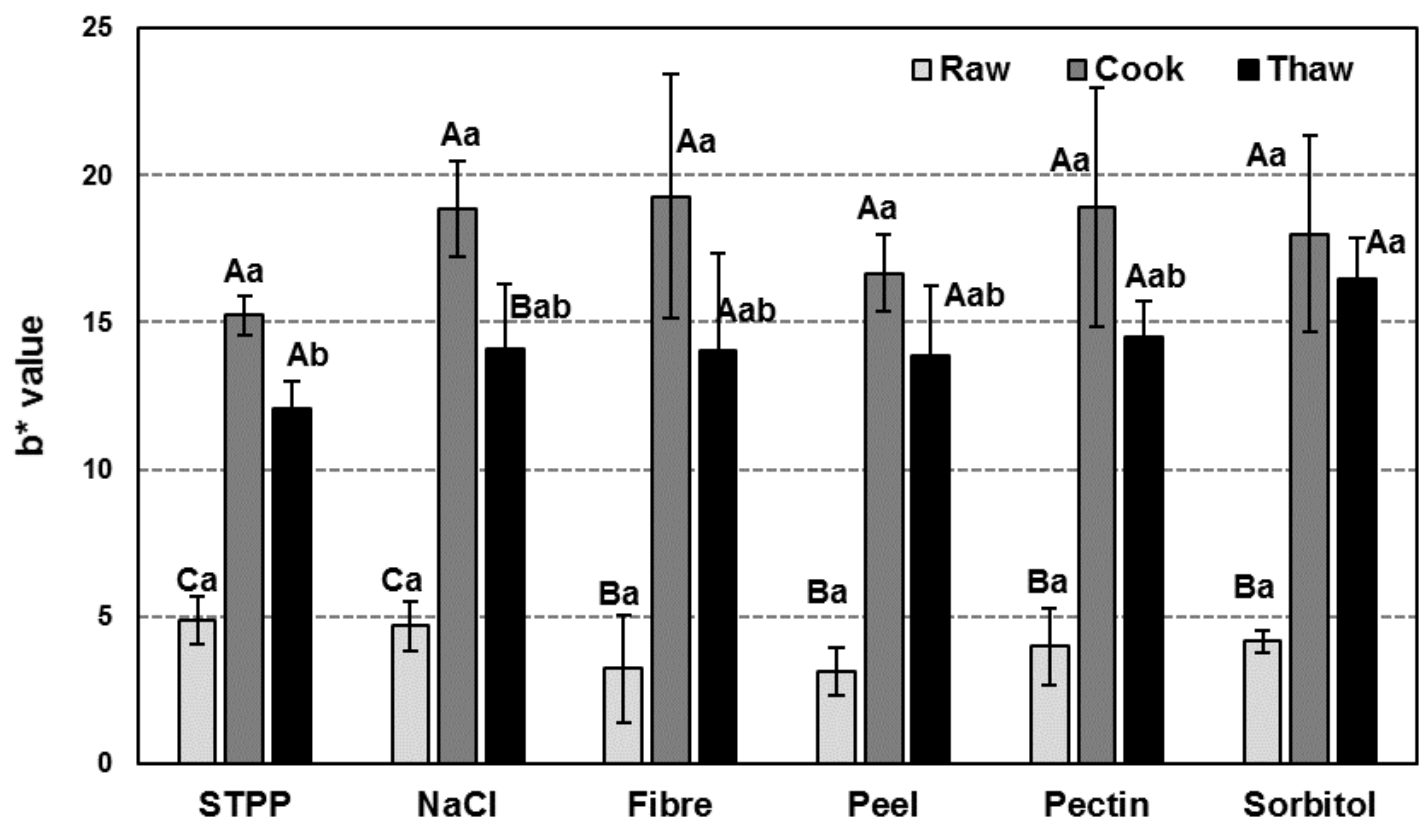

Figure 3: Effect of marinade treatments on yellow colour intensity ( $b^{*}$ value) of chicken breasts. Treatments sharing different letters $(\mathrm{A}, \mathrm{B}, \mathrm{C})$ and $(\mathrm{a}, \mathrm{b})$ were significantly different from each other within the same marinade and across different marinades, respectively $(\mathrm{P}<0.05)$.

Table 4: Shear force of chicken breast marinated in different treatments

\begin{tabular}{lc}
\hline Treatment & Hardness $(\mathrm{N})$ \\
\hline 1. STPP & $10.38 \pm 0.54^{a}$ \\
2. NaCl & $8.39 \pm 0.45^{a b}$ \\
3. Mango peel fibre & $7.13 \pm 1.12^{b}$ \\
4. Mango peel powder & $9.94 \pm 0.73^{a}$ \\
5. Pectin & $8.94 \pm 0.12^{a b}$ \\
6. Sorbitol Syrup & $10.45 \pm 1.17^{a}$ \\
\hline
\end{tabular}

Values are mean \pm standard deviation $(n=3)$. Mean values in the same row sharing different superscripts $(\mathrm{a}, \mathrm{b}, \mathrm{c})$ were significant different $(\mathrm{P}<0.05)$. 
considering the feasibility in use, whole mango peel powder would be a better choice over mango peel fibre, due to the higher yield and lower cost of ingredient preparation. The findings from this study should encourage an interest in utilizing mango peel in the food industry. This would not only add value to the waste, but also incorporate a low-sodium, low-phosphate, and natural plantbased ingredient to address current consumers' requirements.

\section{Acknowledgements}

Thanks are due to technicians from Department of Food Technology and Nutrition, Maha Sarakham University, for providing chemicals and analytical training.

\section{References}

Acton, J. C. \& Jensen, J. M. (1994). Understanding marinade technology. Poult. Proc. 9, 18-21.

Ajila, C. M., Aalami, M., Leelavathi, K. \& Rao, U. J. S. P. (2010). Mango peel powder: A potential source of antioxidant and dietary fiber in macaroni preparations. Innovative Food Science \&6 Emerging Technologies, 11(1), 219-224. doi:10.1016/j.ifset. 2009.10.004

Ajila, C. M., Naidu, K. A., Bhat, S. G. \& Rao, U. P. (2007). Bioactive compounds and antioxidant potential of mango peel extract. Food Chemistry, 105(3), 982-988. doi:10. 1016/j.foodchem.2007.04.052

AOAC. (2005). Official methods of analysis (18th ed.). Association of Official Analytical Chemist. Arlington, VA, USA.

Cheng, Y. F. \& Bhat, R. (2016). Functional, physicochemical and sensory properties of novel cookies produced by utilizing underutilized jering (pithecellobium jiringa jack.) legume flour. Food Bioscience, 14, 54-61. doi:10.1016/j.fbio.2016.03.002

Essmat, A. A.-A., Marwa, H. M. \& Ferial, M. A.-S. (2017). Functional properties of citrus peel as affected by drying methods. American Journal of Food Technolog, 12, 193-200. doi:10.3923/ajft.2017.193.200
Geerkens, C. H., Nagel, A., Just, K. M., MillerRostek, P., Kammerer, D. R., Schweiggert, R. M. \& Carle, R. (2015). Mango pectin quality as influenced by cultivar, ripeness, peel particle size, blanching, drying, and irradiation. Food Hydrocolloids, 51, 241-251. doi:10.1016/j.foodhyd.2015.05.022

Jan, R., Saxena, D. C. \& Singh, S. (2016). Physico-chemical, textural, sensory and antioxidant characteristics of gluten - free cookies made from raw and germinated chenopodium (chenopodium album) flour. LWT - Food Science and Technology, 71, 281-287. doi:10.1016/j.lwt.2016.04.001

Jarvis, N., Clement, A. R., O'Bryan, C. A., Babu, D., Crandall, P. G., Owens, C. M., ... Ricke, S. C. (2012). Dried plum products as a substitute for phosphate in chicken marinade. Journal of Food Science, 77(6), S253-S257. doi:10.1111/j.1750-3841.2012. 02737.x

Kanatt, S. R. \& Chawla, S. P. (2018). Shelf life extension of chicken packed in active film developed with mango peel extract. Journal of Food Safety, 38(1). doi:10.1111/ jfs. 12385

Kermani, Z. J., Shpigelman, A., Huong, T. T. P., Van Loey, A. M. \& Hendrickx, M. E. (2015). Functional properties of citric acid extracted mango peel pectin as related to its chemical structure. Food Hydrocolloids, 44, 424-434. doi:10.1016/j. foodhyd.2014. 10.018

Lee, E. J. \& Ahn, D. U. (2005). Quality characteristics of irradiated turkey breast rolls formulated with plum extract. Meat Science, 71(2), 300-305. doi:10 . 1016 / j . meatsci.2005.03.017

Li, C. T. (2006). Myofibrillar protein extracts from spent hen meat to improve whole muscle processed meats. Meat Science, 72(3), 581-583. doi:10 . 1016/j . meatsci . 2005.08.008

Nagel, A., Mix, K., Kuebler (Nee Wulfkuehler), S., Bogner, H., Kienzle, S., Elstner, P., ... Neidhart, S. (2015). The arabinogalactan of dried mango exudate and its coextraction during pectin recovery from mango peel. Food Hydrocolloids, 46, 134143. doi:10.1016/j.foodhyd.2014.11.029 
Nunez de Gonzalez, M. T., Boleman, R. M., Miller, R. K., Keeton, J. T. \& Rhee, K. S. (2008). Antioxidant properties of dried plum ingredients in raw and precooked pork sausage. Journal of Food Science, 73(5), H63-H71. doi:10.1111/j.17503841.2008.00744.x

Rolin, C. (1993). Pectin, industrial gums: Polysaccharides and their derivatives. Academic Press, New York.

Tarté, R. (2009). Meat-derived protein ingredients. (pp. 145-171). doi:10.1007/978-0387-71327-4_7

U-chupaj, J., Malila, Y., Petracci, M., Benjakul, S. \& Visessanguan, W. (2017). Effect of tumbling marination on marinade uptake of chicken carcass and parts quality. Brazilian Journal of Poultry Science, 19(1), 61-67. doi:10.1590/1806-9061-20160380

Wang, M., Huang, B., Fan, C., Zhao, K., Hu, H., $\mathrm{Xu}, \mathrm{X} ., \ldots$ Liu, F. (2016). Characterization and functional properties of mango peel pectin extracted by ultrasound assisted citric acid. International Journal of Biological Macromolecules, 91, 794-803. doi:10.1016/ j.ijbiomac.2016.06.011

Zheng, M., Toledo, R. \& Wicker, L. (1999). Effect of phosphate and pectin on quality and shelf-life of marinated chicken breast. Journal of Food Quality, 22(5), 553-564. doi:10.1111/j.1745-4557.1999.tb00186.x 